$\mathbb{T}$ periodica polytechnica

Civil Engineering

$54 / 1(2010) 3143$

doi: 10.3311/pp.ci.2010-1.04

web: http://www.pp.bme.hu/ci

(c) Periodica Polytechnica 2010

RESEARCH ARTICLE

\section{Laboratory and virtual experiments on C-section compression members with semi-rigid connections}

\author{
Gábor Jakab / László Dunai
}

Received 2009-06-09, accepted 2009-07-01

\begin{abstract}
In this paper results of an ongoing research on cold-formed $C$-section members are presented. The research aims the development of design methods for structural arrangements directly not covered by the standard, based on laboratory tests and numerical modelling. In the paper laboratory tests on $C$-section compression members are presented: arrangement, behaviour modes and load-bearing capacities. The behaviour of the specimens as well as the effect of the non-rigid end support provided by the self-drilling screws used to introduce load in the specimens are discussed. A numerical model capable of geometrically and materially nonlinear, imperfect analysis to reproduce the tests is introduced with a focus on the modelling of the connector elements and imperfections. An approach to model selfdrilling screws and equivalent geometrical imperfections is presented; the applicability of the model is shown. It is shown, that screw stiffness and geometrical imperfections both influence the stiffness of the models. The calibration of the model is carried out using the results of the experimental tests introduced previously; the results of these virtual experiments are presented.
\end{abstract}

\section{Keywords}

cold-formed section · laboratory test - semi-rigid connection · self-drilling screw · geometrical imperfections $\cdot$ connection rigidity $\cdot$ numerical model

\section{Acknowledgement}

The authors hereby gratefully acknowledge the financial support of the OTKA T049305 project and the specimens provided by Lindab Hungary Ltd. to carry out the laboratory tests.

\section{Gábor Jakab}

Department of Structural Engineering, BUTE, Bertalan L. u. 1, Budapest, H1111, Hungary

e-mail: gjakab@vbt.bme.hu

\section{László Dunai}

Department of Structural Engineering, BUTE, Bertalan L. u. 1, Budapest, H1111, Hungary

e-mail: ldunai@epito.bme.hu

\section{Introduction}

The presented work is part of an ongoing research on coldformed C-section members widely used in the building practice. Within the confines of this work 96 tests were carried out at Budapest University of Technology and Economics on Csection compression members with supporting conditions and cross-sectional arrangements directly not covered by Eurocode 3 (EC3) but used in building systems. The tests' aim is to study the stability behaviour of the specimens, obtain and characterize their failure modes and to derive EC3-based design methods for them. In addition to the laboratory tests shell finite element (FE) models were developed to complement the laboratory tests, thus enable widening the range of applicability of the design methods by means of virtual tests.

The traditional testing approach in case of cold-formed compression members is to provide near-ideal supports and load introduction (ball bearing, thick plates, etc.), to make the comparison of test and model easier [1]. However, due to the structural arrangements usually applied in real structures load introduction is rarely ideal, hence applying the derived design formulae on them usually leads to compromises, thus conservative design. Although the recent advance of available computational power makes the use of detailed numerical models possible, the use of advanced numerical models - shell finite element models - to simulate experiments on structures or parts of structures made of cold-formed members is rare [2], for two reasons.

First, cold-formed members are highly imperfection sensitive; imperfections must be included in the model to obtain the real behaviour and load-bearing capacity. Imperfections may be incorporated in the model based on real - measured - geometrical and mechanical imperfections of each specimen, or by applying equivalent geometrical imperfections. The former method is very demanding and poses difficulties, especially in the case of larger structures, for the latter no unified approach suited for cold-formed members similar to that included in Eurocode 3 Part 1-5 for plated structures [3] is present.

Second, the connector elements used in cold-formed structures - frames, trusses, etc. - result semi-rigid structural joints that influence the global behaviour of these, and in most cases 
cause interaction between the joints and the connected members. However, no generally applicable model of the connector elements exists that can be incorporated in shell FE models to accurately predict both global and local behaviour of cold-formed structures. Nevertheless, a consistent solution for the question of equivalent imperfections may only be provided once the problem of modelling the semi-rigid structural joints is solved. Analytical solutions for similar problems have been presented in [4,5].

In this paper a model suiting the needs of virtual experimenting on cold-formed C-section members and structures is presented. A simple test arrangement covered by the application rules of EC3 Part 1-3 [6] is used as basis to develop the model: single $\mathrm{C}$-section specimens with eccentric load introduction at the ends. The test results available provide a wide basis to model development and validation, the arrangement is simple enough to make a first step towards more complex problems and the results can easily be compared to the standard. In the paper a model capable of following the non-rigid behaviour of self-drilling screws is described. Equivalent geometrical imperfections based on shapes generated using the constrained finite strip method are applied to the models. The applicability of the modelling approach presented in the paper to carry out virtual experiments is verified based on results of tests specimens with different lengths and cross-sections.

\section{Tests on cold-formed C-section members}

\subsection{Test programme}

Laboratory tests on C-section compression members were carried out in two sets using the testing frame setup in the Structural Laboratory of the Department of Structural Engineering (Fig. 1). The specimens were placed vertically in the rig, and loaded at the lower support using a hydraulic jack. A detailed description on the test arrangement and measurement system is to be found in [7] and [8].

The test programme consisted of 96 tests on specimens with different load introduction and support detailing. Member lengths of 800, 1500, 2000, 2500 and $3600 \mathrm{~mm}$ were used. Five different sections having web plate width-to-thickness ratio $(b / t)$ ranging 80-200 were used in the tests. Dimensions of the crosssections used are listed in Table 1 .

A selection of the investigated specimen configurations is shown in Fig. 2, with the arrangement discussed in this paper highlighted. These specimens are single $\mathrm{C}$-section members with the load introduced at the ends by means of gusset plates (wing-plate stiffened plates of $6 \mathrm{~mm}$ thickness) and SFS-SD6 type self-drilling screws (Fig. 3). The internal actions of these specimens are axial compression and bending about the weak axis - resulting from the eccentricity of the load introduction ,with the web in compression. The eccentricity may be taken equal to the distance of the centroid of the section to the outer fibre of the web. The number of screws was calculated based on the expected load-bearing capacity of the given specimen, but

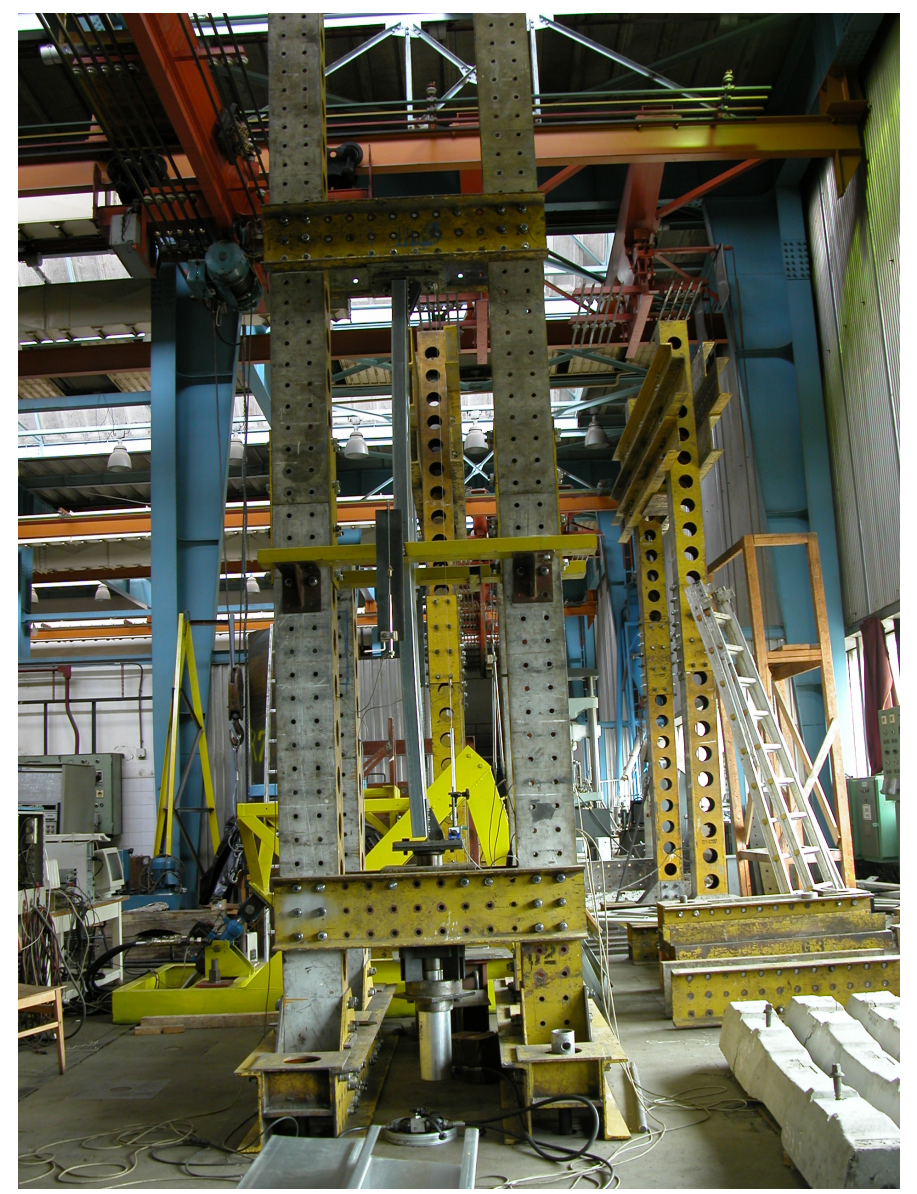

Fig. 1. Test rig

usually more screws were used than necessary, to avoid screw failure at load introduction. Typical screw layouts are shown in Fig. 4 .

The main characteristics of the tests specimens are to be found in Table 2

\subsection{Experimental behaviour}

The first sign of the applied load in case of the specimens was the local buckling of the web along the full specimen length, which was followed by the flexural buckling of the member about its minor axis. The final failure was caused by plastic plate buckling - a plastic mechanism - at the member half-length (Fig. 5). Note that specimens with a length of $800 \mathrm{~mm}$ and the same end supporting configuration were also tested, but as the failure mode obtained from these tests was local failure caused by the interaction of web crushing and screw failure, these were excluded from the current study.

In the load introduction area uniform tilting of the screws occurred, but no deformations of the web between the screws were observed, which leads to the conclusion, that shear force distribution between the screws is approximately uniform. In some tests the separation of the web of the specimen and the gusset plate occurred, leading to change in the eccentricity of the load introduction. Based on these observations, the support provided by the screws is non-rigid in the in-plane and out-of-plane di- 
Tab. 1. Section dimensions

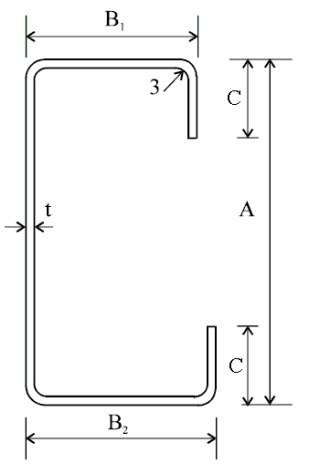

\begin{tabular}{|c|c|c|c|c|}
\hline $\mathrm{A}[\mathrm{mm}]$ & $\mathrm{t}[\mathrm{mm}]$ & $\mathrm{B} 1[\mathrm{~mm}]$ & $\mathrm{B} 2[\mathrm{~mm}]$ & $\mathrm{C}[\mathrm{mm}]$ \\
\hline \multirow{4}{*}{200} & 1.0 & & & 19.7 \\
\hline & 1.5 & 66 & 74 & 21.2 \\
\hline & 2.0 & & & 22.8 \\
\hline & 2.5 & & & 24.4 \\
\hline
\end{tabular}
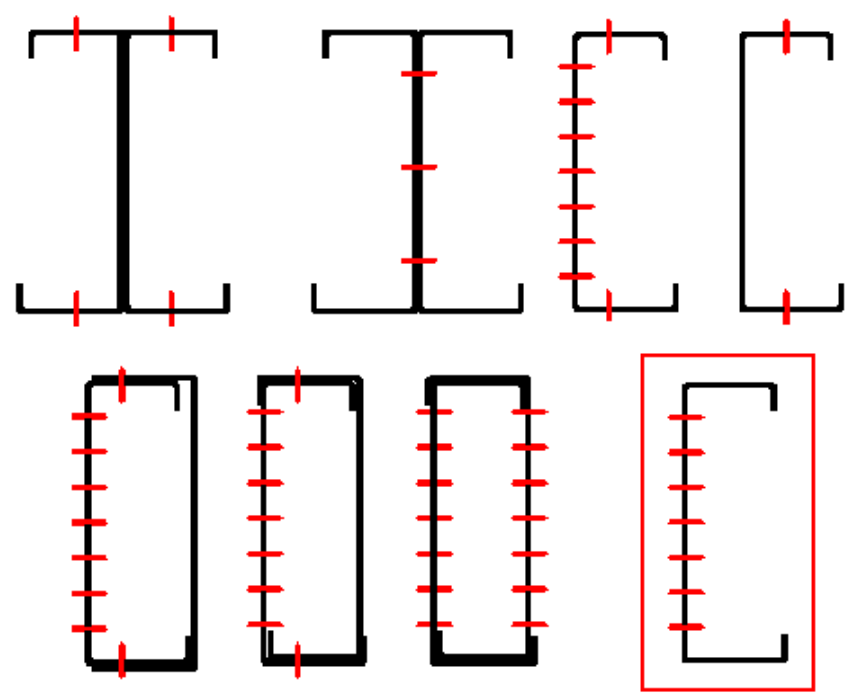

Fig. 2. Specimen configurations with the studied arrangement highlighted
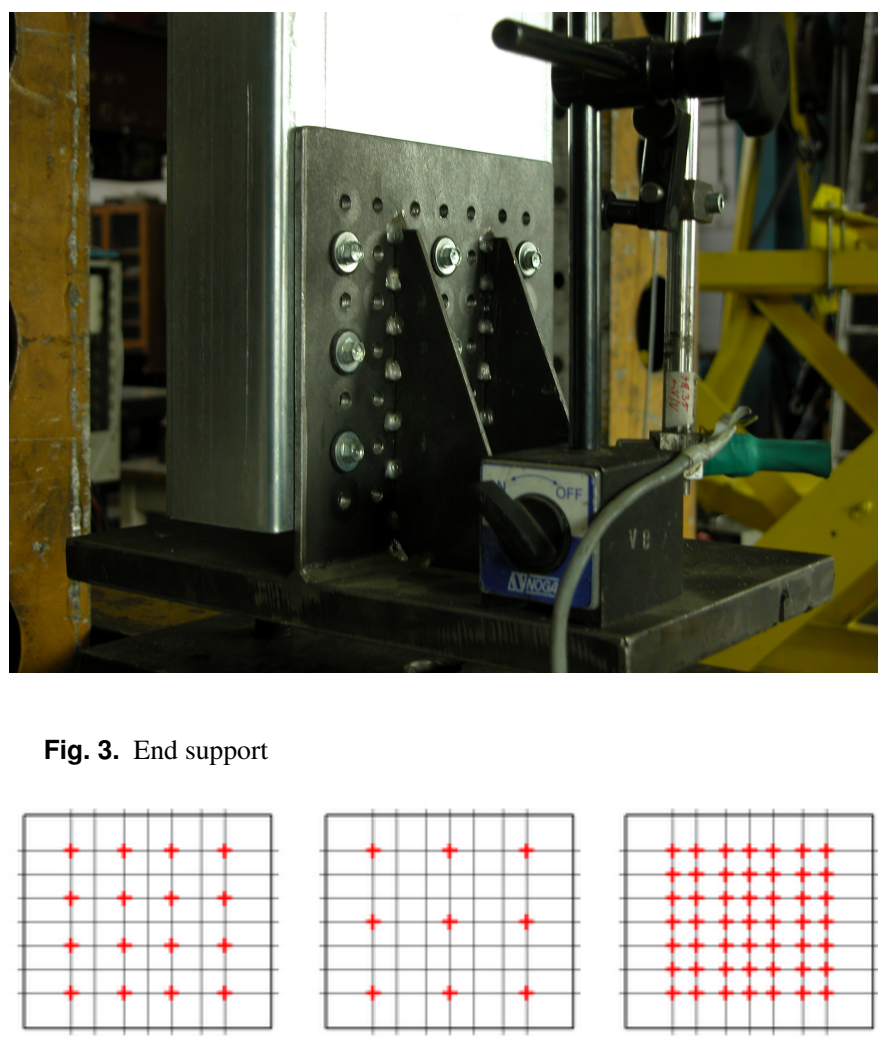

Fig. 4. Typical screw layouts
Tab. 2. Specimen characteristics and test results

\begin{tabular}{|c|c|c|c|c|c|}
\hline Test & Section & $\begin{array}{l}\text { Length } \\
\text { [mm] }\end{array}$ & $\begin{array}{l}\text { Number } \\
\text { and } \\
\text { layout of } \\
\text { screws }\end{array}$ & $\begin{array}{c}\text { Load- } \\
\text { bearing } \\
\text { capacity } \\
{[\mathrm{kN}]}\end{array}$ & $\begin{array}{c}\text { Failure } \\
\text { mode }\end{array}$ \\
\hline C12 & C200/2.0 & \multirow{2}{*}{2000} & $20(5 \times 4)$ & 71.10 & \multirow{12}{*}{ 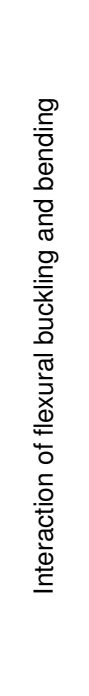 } \\
\hline C15 & C200/1.0 & & $8(2 \times 4)$ & 24.20 & \\
\hline $\mathrm{C} 23$ & C200/2.0 & \multirow{2}{*}{3600} & $9(3 \times 3)$ & 46.80 & \\
\hline C26 & C200/1.0 & & $6(2 \times 3)$ & 17.20 & \\
\hline $\mathrm{C} 40$ & C200/1.5 & \multirow{3}{*}{2500} & $9(3 \times 3)$ & 41.02 & \\
\hline C41 & C200/2.0 & & $12(4 \times 3)$ & 63.99 & \\
\hline C42 & C200/2.5 & & $20(4 \times 5)$ & 94.34 & \\
\hline C66 & C200/2.0 & \multirow{5}{*}{1500} & $16(4 \times 4)$ & 78.97 & \\
\hline C67 & C200/2.5 & & $25(5 \times 5)$ & 111.10 & \\
\hline C80 & C200/2.5 & & $16(4 \times 4)$ & 114.24 & \\
\hline C81 & C200/2.0 & & $9(3 \times 3)$ & 79.23 & \\
\hline C82 & C200/2.0 & & $49(7 \times 7)$ & 78.86 & \\
\hline
\end{tabular}

rection as well, but the in-plane rigidity governs the behaviour (Fig. 6. Note, that in the case of a compression member the in-plane rigidity of the end connection (that is, the rigidity of the end support in the direction of the applied load) has little effect on the load-bearing capacity, as the buckling length is not affected by this.

On Fig. 7 screw layouts and force-shortening diagrams of tests C66, C81 and C82 are shown, that were carried out to study the effect of different screw numbers on specimens of the same length and section. It is found, that the failure mode and loadbearing capacity of these test specimens is unaffected by the number of screws used, but the initial stiffness of the specimens gets greater with the increasing number of screws. A complete list of test results can be found in Table 2 .

\section{Numerical modelling}

\subsection{Modelling concept}

The method for the numerical modelling of cold-formed members using shell elements is available: previous studies show, that geometrically and materially nonlinear, imperfect 

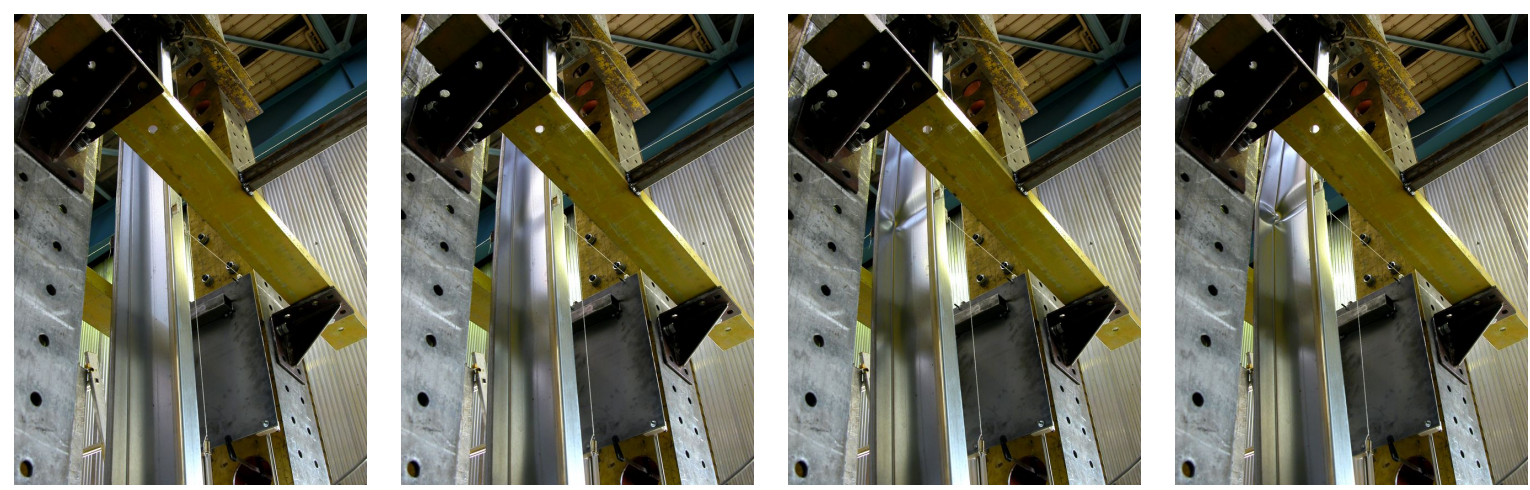

Fig. 5. Behaviour and failure mode (C41)
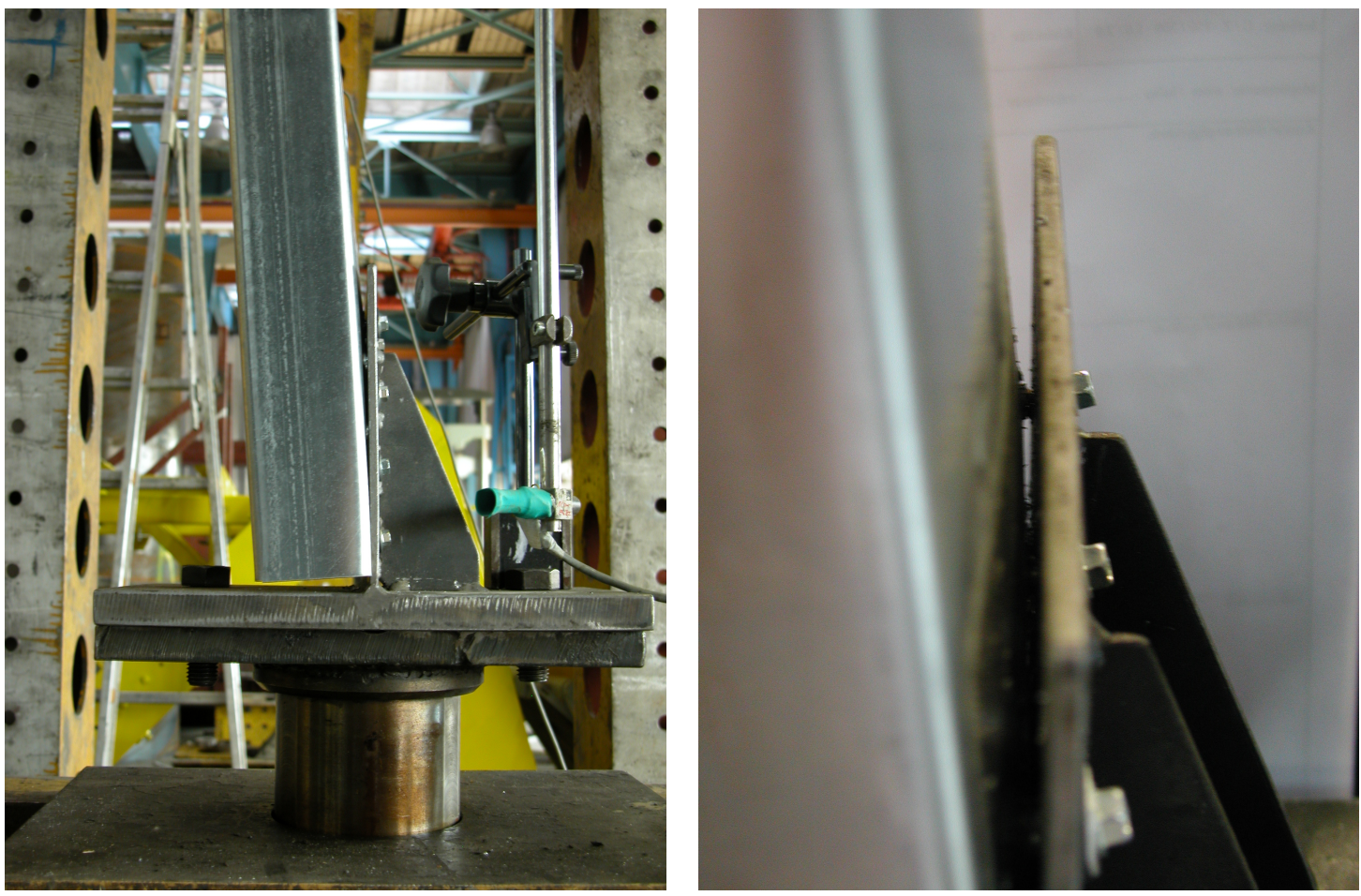

Fig. 6. Rotation of the end connection (left); tilted self-drilling screws (right)
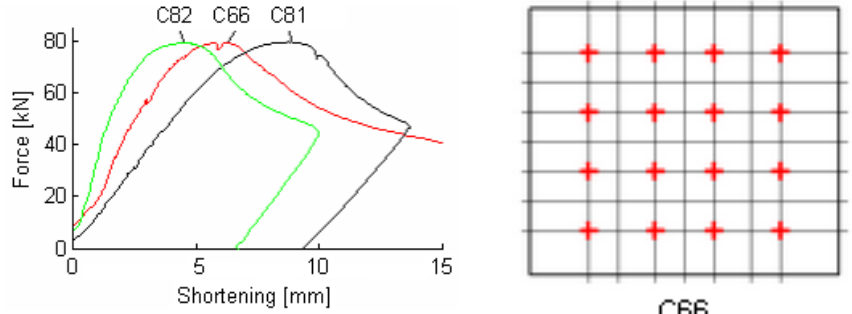

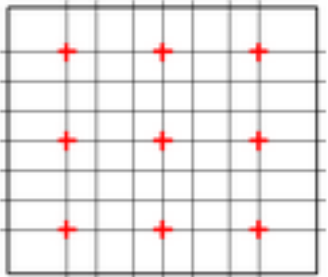

$\mathrm{C} 81$

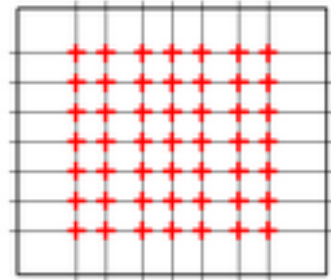

$\mathrm{C82}$

Fig. 7. Screw layout and measured force-shortening diagrams 
analysis (GMNIA) is possible using almost any major FE program capable of handling shell elements and supporting nonlinear material behaviour and large displacements. This makes the FE simulation of laboratory tests with simple supporting conditions possible [9].

A numerical model is considered verified if stiffness, loadbearing capacity and the failure mode obtained from an analysis is in good accordance with the results obtained in a laboratory test. To accurately predict the global and local behaviour of a structure with semi-rigid structural joints (i.e.: made using self-drilling screws) the force-displacement or moment-rotation characteristics of these must be modelled. Note that a very accurate modelling of joint areas is nearly impossible, since the initial conditions of the joints-exact geometry, torque used to fasten the screws, etc. - are usually not known. A model capable of accurately predicting the stress distribution in the vicinity of a screw is unnecessary since this is of lesser importance from the global behaviour point-of-view. However, a qualitatively correct local behaviour of the screw model is necessary since this makes an accurate prediction of the semi-rigid joint behaviour possible, thus a model physically correct in every detail (i.e. geometrical details, contact surfaces, solid elements, etc.) is unnecessary; a calibrated screw model made using elements compatible with shell elements may be used.

Note, that the present problem would not necessarily need a well-calibrated screw model to accurately reproduce the loadbearing capacities obtained in the laboratory tests, since the shear rigidity of the end support - that is, the rigidity of the support in the direction of the member axis - does not affect the buckling length, and the rotational rigidity of this support is approximately the same in each case. However, the studied test specimens are simple, yet provide a wide parameter space to develop a model that can be used in FE models of other structures, thus prove the viability of the concept.

\subsection{Global numerical model}

The numerical model of the laboratory tests was developed using the finite element software package Ansys 11.0 [10].

The geometrical model of the specimens, including the dimensions of the $\mathrm{C}$-section and the gusset plate as well as plate thicknesses and position and diameter of the screw holes is generated corresponding to the real test specimen.

The C-section member and the gusset plates are modelled using 4-node 24-DOF's shell elements (SHELL181) with a bilinear (linear elastic-kinematic hardening plastic) material model derived from coupon tests in accordance with the recommendations in [3]. The material properties measured and those applied in the model are shown in Fig. 8 and Fig.9. The applied average element edge lengths are summarized in Fig. 10 and Table 3 The geometrical model is generated to be perfect; imperfections are added by the appropriate change of node locations after mesh generation. Details on the applied imperfections are given in Section 3.4

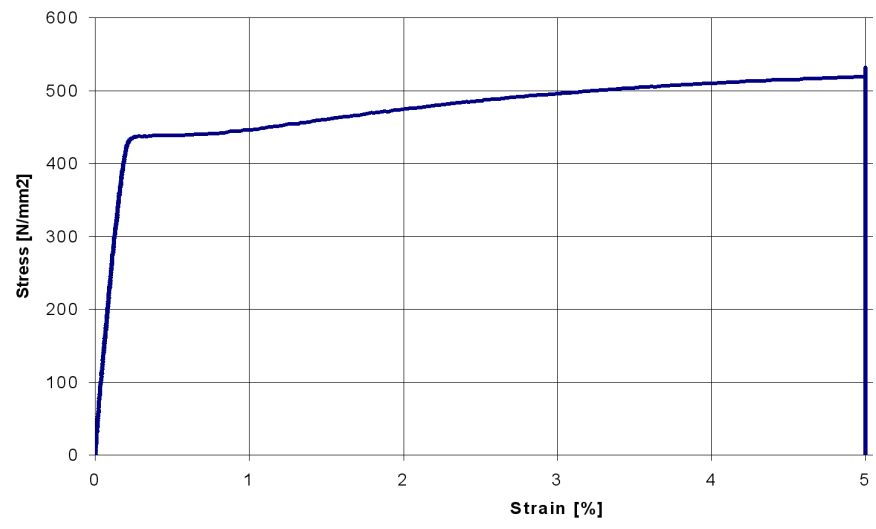

Fig. 8. Measured $\sigma-\varepsilon$ diagram (f $\left.\mathrm{f}_{y}=437 \mathrm{MPa}\right)$

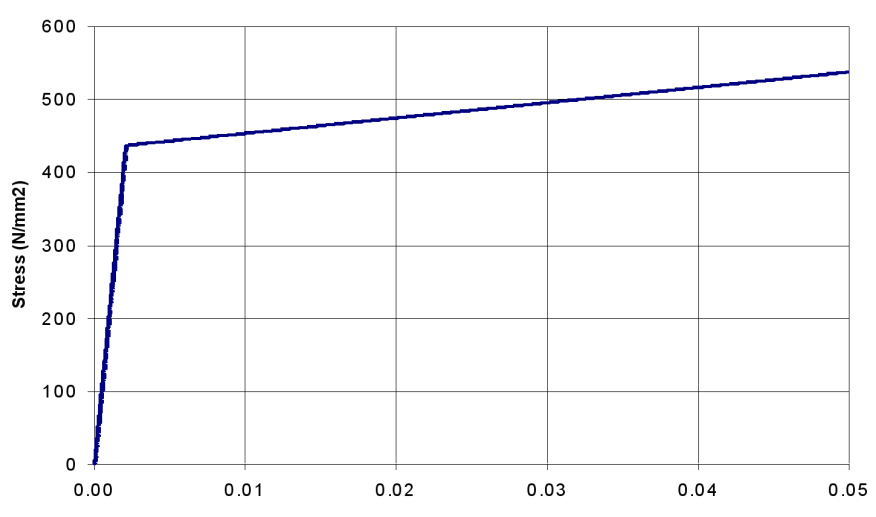

Fig. 9. Material model $\left(f_{y}=437 \mathrm{MPa}, \mathrm{E}_{1}=210000 \mathrm{MPa}, \mathrm{E}_{2}=2100 \mathrm{MPa}\right)$

Tab. 3. Applied average element edge lengths

\begin{tabular}{cccc}
\hline & Zone 1 & Zone 2 & Zone 3 \\
\hline Position of zone & $\begin{array}{c}\text { From end of } \\
\text { specimen to } \\
180 \mathrm{~mm}\end{array}$ & $\begin{array}{c}\text { From 180 mm to } \\
\mathrm{L} / 2-\mathrm{h}_{\mathrm{w}}\end{array}$ & $\begin{array}{c}\text { Between L/2- } \mathrm{h}_{\mathrm{w}} \\
\text { and L/2+hw }\end{array}$ \\
\hline $\begin{array}{c}\text { Average } \\
\text { element edge } \\
\text { length }\end{array}$ & $10 \mathrm{~mm}$ & $15 \mathrm{~mm}$ & $8 \mathrm{~mm}$ \\
\hline
\end{tabular}

Contact surfaces at the gusset plate are modelled using CONTA173 and TARGE170 surface-to-surface contact and target elements in a symmetric arrangement. To achieve better numerical stability the mesh on the contacting surfaces are congruent and the contact is assumed to be frictionless. The connector elements are modelled using beam elements detailed in Section 3.3. Load is applied through the nodes of the sole of one of the gusset plates as kinematic constraint $-20 \mathrm{~mm}$ displacement in the axial direction to cause compression in the member. Vertical and horizontal supports are applied at all corners of the gusset plate soles. The model details - the gusset plate, the contact surfaces, the C-section and the screws - are shown in Fig. 11 .

To solve the model a static analysis was carried out taking into account large deformations, the default Newton-Ralphson iteration procedure was used with the sparse matrix solver cho- 

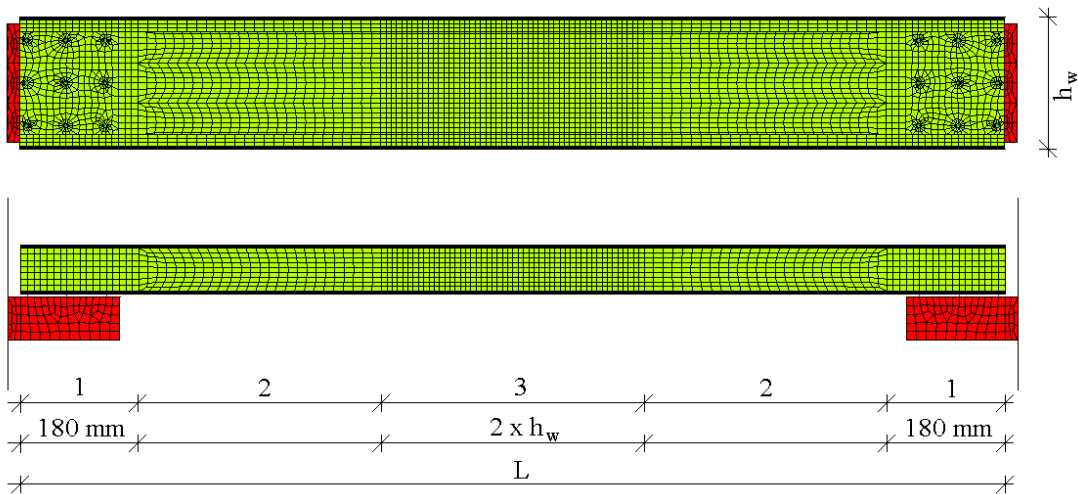

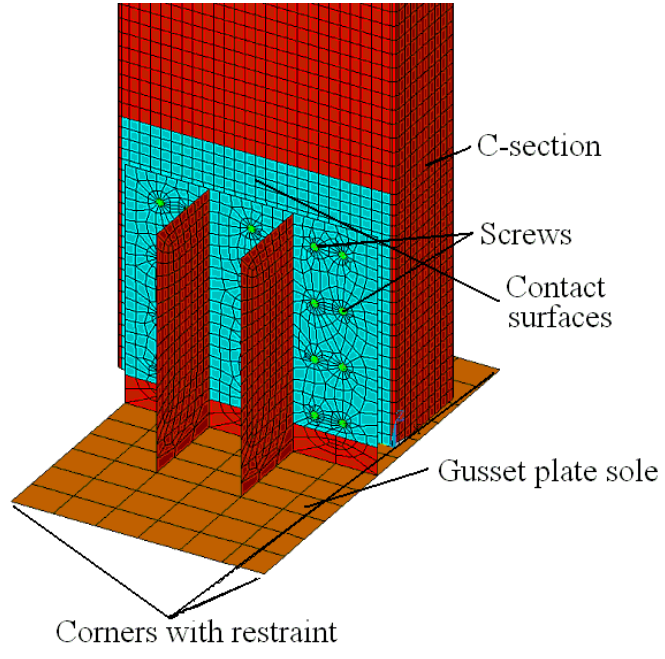

Fig. 11. Detail of the FE model

sen automatically by the ANSYS solver routine. Line search and time stepping options were set to be chosen automatically as well.

A MATLAB-based [11] pre- and post-processing program was developed to generate input macros enabling fast model generation and result evaluation.

\subsection{Numerical model of self-drilling screws}

The screw model developed consists of 2-node 12-DOF's beam elements (BEAM4): one element represents the shaft of the screw; this is connected to the rim of the screw hole by radial elements, as shown in Fig. 10. The material model of each element is linear elastic. The rim of the screw hole is divided in 16 segments of equal length. The shaft element's crosssectional properties (area, moments of inertia) are derived from the screw shaft diameter. Shear deformations of the shaft element are taken into account; radial elements are set to have no shear deformations. The model can be calibrated by choosing the appropriate values of the cross-sectional area and moments of inertia of the radial beam elements and the shear area of the shaft element.

As no contact elements are used in the screw model, failure modes involving separation of the screw and the connected plates are not covered by the model. However, the phenomena observed during the tests on $\mathrm{C}$-section members can be followed

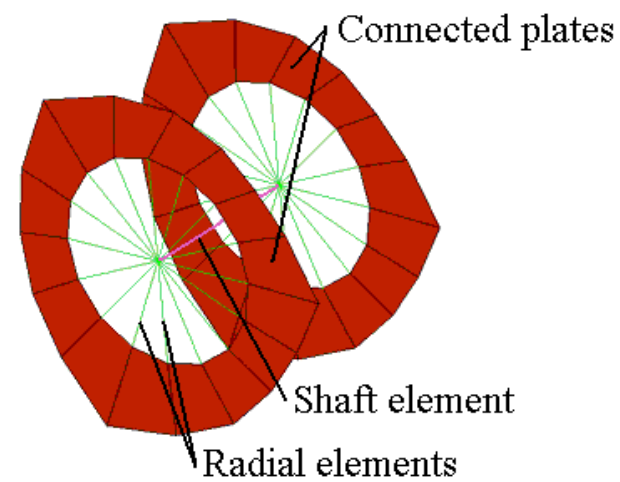

Fig. 12. Screw model

using the model as it has all basic properties necessary for this: the shaft is more rigid than the plates and the radial elements are connected to the shell elements similar to that in the reality. The separation of the connected plates is allowed, as the bending deformation of the radial elements makes the pull-out of the screws possible. The tilting of the screw is modelled by the shear deformations of the shaft element. This way, the model is capable of following the change of eccentricity resulting from the relative displacements of the connected plates. Note, that modelling the screw behaviour would pose considerable difficulties if spring elements or constraint equations were used.

The calibration of the model should be based on tests on structural members; single lap shear tests on connections containing one to three self-drilling screws, however, are not well suited for this purpose, as the rigidities of the screws may scatter (i.e. different torques applied during fastening) and local effects may also strongly influence the behaviour of an individual screw, but such phenomena have less effect if screw groups are used.

\subsection{Modelling of imperfections}

Imperfections of the real specimen are modelled by carrying out the analyses on a geometrically imperfect model that covers the effect of mechanical imperfections - residual stresses and the hardening of the material in the corner areas due to the manufacturing process - and real geometrical imperfections. The approach is conceptually the same as that of the equivalent geometrical imperfections [3], but the aim is not to directly derive design values using them, but to reproduce the behaviour 
and load-bearing capacity of the test specimens. The applied imperfections are not based on measured shape. It is typical to apply the model eigenshapes for geometrical imperfections. In the case of the studied problem, however, these are mainly coupled modes, thus they do not provide the possibility of an imperfection sensitivity analysis, as the weights of the pure local, distortional, global-buckling modes in the eigenshapes of the model are not known. Furthermore, as the eigenshapes calculated depend on the discretization (i.e.: mesh quality, screw layout), any finding regarding the behaviour of the numerical model of a given test can not be directly applied to another test's model.

Pure buckling modes of prismatic members can be obtained by two methods conceptually different, but leading to the same result: a GBT-based approach [12] and constrained finite strip method, a special version of the finite strip method (FSM) [13]. Computer programs utilizing the theories are available for both methods: GBTUL [14], CUFSM [15]. In the current research imperfection modelling is based on CUFSM.

Finite strip method can be used to calculate the bifurcation point of the stability path of a geometrically perfect member for a given stress distribution. The results of an FSM analysis are the load factor, which is a multiplier to the stress distribution to calculate the critical stress of the member for a given buckling length, and the buckling shape of the cross-section that refers to the failure mode for that length (Fig. 13. FSM analyses are usually carried out on a set of buckling lengths covering all three pure modes to create the so called buckling curve, that provides insight into the stability behaviour of the studied member by showing the change of the load factor and buckling shape in function of the buckling length (Fig. 14 top). The buckling modes are either local, distortional or global modes, that may or may not appear among the shapes, depending on the applied stress distribution and the shape of the cross-section. In the majority of the cases the pure modes couple, hence deciding which mode a given shape belongs to may be difficult and certainly not objective. The constrained finite strip method (cFSM) is an extension to FSM that can be used to determine the weights of the pure modes in a given mode by decoupling the modes and calculating the modal participation of the pure modes (Fig. 14 . bottom) in a buckling shape.

The imperfect shape applied to the numerical model is generated using the results of a cFSM analysis by choosing buckling shapes and lengths resulting from the cFSM analysis and dragging them along the member using a sinusoidal line as path, by modifying the coordinates of the nodes. The FSM model of the test specimens - the cross-section, including the radii in the corners - is defined using CUFSM's built-in template. As the described method is merely used to generate an imperfect shape, the stress distribution applied to obtain the buckling shapes must not be conforming to that in the real test. In the current study a uniform stress distribution is applied to obtain local, distortion and global buckling shapes.

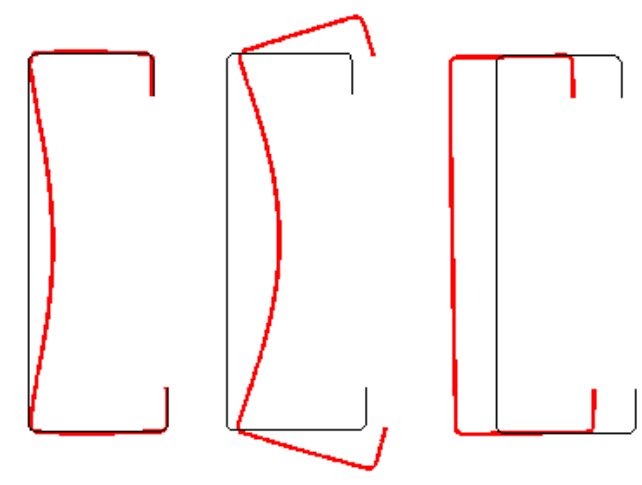

Fig. 13. Local, distortional and global buckling shapes (left to right)

The shapes to be used are to ones belonging to the local minima of the local and distortional modes in the buckling curve - the buckling lengths where the mode gives most part of the shape. Global buckling has no local minimum, in this case a buckling length long enough to be considered pure mode - ten times the member length - is used.

As in a real test only full buckling half-waves appear, during modifying the perfect geometry care must be taken to have only full half-waves in the imperfect geometry. This needs different considerations in the case of each buckling mode as follows.

In the case of global buckling one sinusoidal half-wave is applied as dragging path, and all nodes of the FE model are relocated.

In the case of local buckling only a portion of the nodes is modified, those between the end supports. The position of the waves is calculated based on this length to fit the highest number of half-waves in the region (Fig. 15). This method does not generate local buckling waves at the end supports of the member and leaves a portion (shorter than the half of the buckling length applied at each end) of the sections perfect.

In the case of distortional buckling the member length is divided by the half-wavelength derived from cFSM and the result is rounded towards the nearest integer. This way the number of half-waves to be applied is set, resulting in a new buckling length - that is, the one providing full-waves and being close to the real minimum of the curve of pure distortional buckling. To have the pertinent buckling shapes and buckling lengths cFSM is once again used to determine the buckling shape for this new length. The nodes of the FE model are then modified using the newly calculated buckling shape and a sinusoidal wave with the calculated number of full half-waves to generate the imperfect shape.

The total imperfect shape to be applied to the C-section member is generated by a weighted superposition of the shapes generated for the individual buckling modes. The resulting shape is almost symmetric; a slight asymmetry is present due to the different flange sizes. Fig. 13 shows an imperfect shape generated from local, distortional and global shapes applied to the model.

The main advantage of this approach is an easy implementation (as CUFSM is an open-source software it can be integrated 

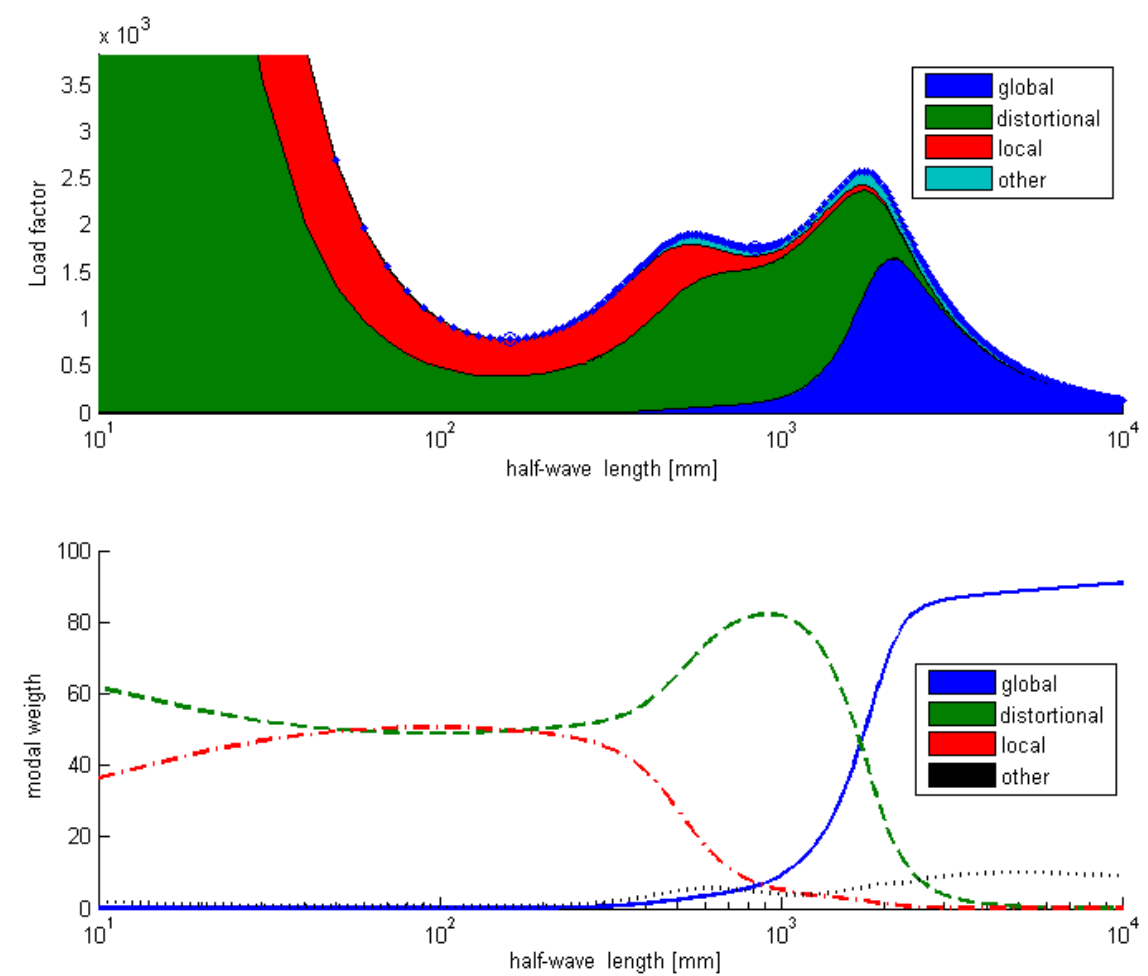

Fig. 14. Buckling curve with modal participation (top), curves of modal weights (bottom)

in the pre-processor) and a certain level of consistency regarding the otherwise usually arbitrary choice of imperfect shape. The shapes generated this way are similar to those obtained from an eigenvalue analysis of the FE model and the applied pure shapes and their magnitudes are known and can be controlled. This makes studying the imperfection sensitivity of the members possible, as the properties (amplitude, wavelength) of the pure shapes applied to the model may be treated as parameters. It is to be noted, that recent research on eigenshape classification using FEM, also going on [16] shows great promise to determine the weigths of pure buckling modes in eigenshapes. A comparison of the proposed approach and the eigenshape-based approach is out of scope of this paper, but is definitely worth investigating. Note, that this is a general approach that can be used to apply buckling shapes in a controlled way regardless of the studied problem, therefore may be applied to other types of members with different cross-sections as well.

\section{Calibration of the model}

\subsection{Calibration of the screw model}

A parametric study was carried out to determine the appropriate values for the elements in the screw model using results of tests $\mathrm{C} 81$ and $\mathrm{C} 40$. The numerical model of the test specimen was generated as described before, with perfect geometry. This was necessary because it was suspected, that geometrical imperfections influence the stiffness of the model, and the aim of the study was to provide insight how different settings of the elements in the screw model affect the global behaviour of the model.
The settings used during the parametric study are listed in Table 4 Figs. 16 and 17 show the resulting force-axial shortening diagrams. Fig. 18 shows the deflected shape of a screw for different settings to provide insight how different settings influence the behaviour. Fig. 19 shows the failure mode obtained from the analysis with the settings listed in Table 5

From the results the following conclusions can be drawn: i) by changing the properties of the elements in the model, the connection rigidity can be tuned within wide range, ii) the failure mode of the member is in all cases the same as the one obtained in the laboratory test, iii) connection rigidity is primarily governed by the shear stiffness of the shaft element, iv) rigidities of the radial elements influence the non-linear behaviour, $v$ ) the numerical stability and convergence speed of the model is sufficient.

Load-bearing capacities obtained from the parametric study scatter, but are little affected by the connection rigidity as shown in Table 5

Similar parametric studies - although in a narrower parameter space - were carried out using results of more tests to find the settings resulting in conforming force-displacement diagrams of the test and models. Among the suiting parameter sets for the further studies a choice was made based on the speed of convergence.

The settings chosen are listed in Table 6 The forceshortening diagrams resulting using these settings for tests $\mathrm{C} 40$ (C200/1.5, 9 screws, L=2500 mm) and C82 (C200/2.0, 49 screws, $\mathrm{L}=1500 \mathrm{~mm}$ ) are in good accordance with the mea- 


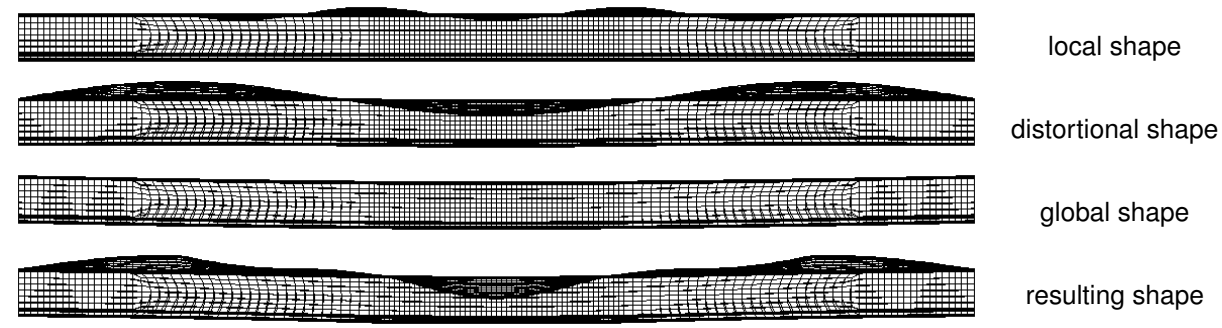

Fig. 15. Applied local, distortional and global shapes and the resulting shape. For illustration, amplitude is in all cases $10 \mathrm{~mm}$

Tab. 4. Settings of the elements of the screw model

\begin{tabular}{ccccc}
\hline & Area $\left[\mathrm{mm}^{2}\right]$ & Shear area divide ${ }^{1}$ & $\begin{array}{c}\text { Moments of inertia } \\
\text { (bending) }\left[\mathrm{mm}^{4}\right]\end{array}$ & $\begin{array}{c}\text { Moment of inertia } \\
\text { (torsion) }\left[\mathrm{mm}^{4}\right]\end{array}$ \\
\hline Shaft element & $\mathrm{r}^{2} \pi$ & $1 ; 10 ; 100 ; 1000$ & $\mathrm{r}^{4} \pi / 4$ & $\mathrm{r}^{4} \pi / 4$ \\
\hline \multirow{3}{*}{ Radial elements } & $0.1 ; 1 ; 10 ; 100$ & 0 & $0.0001 ; 0.001 ;$ & \\
& & & $0.01 ; 0.1 ; 1 ; 10 ;$ & 1 \\
\hline
\end{tabular}

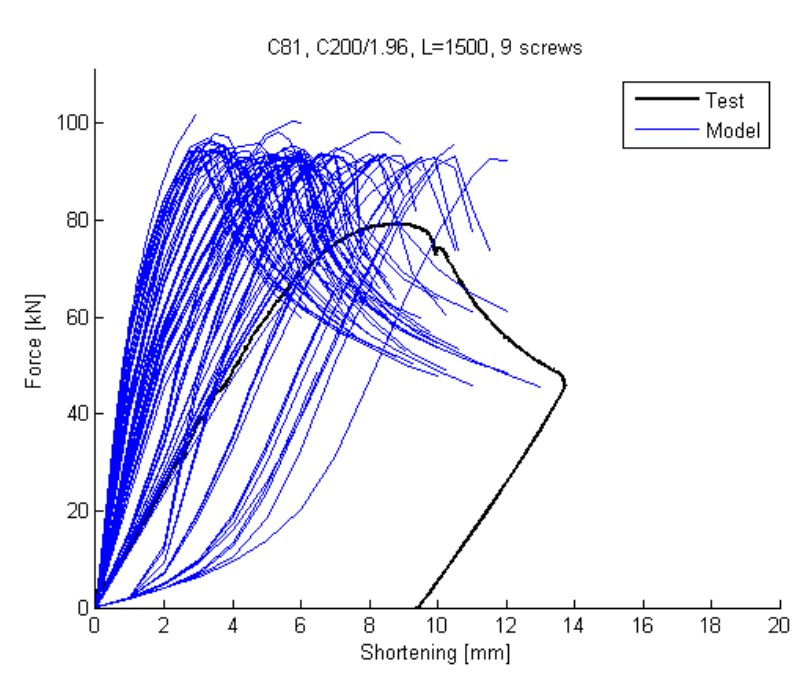

Fig. 16. Results of the parametric study (C81)

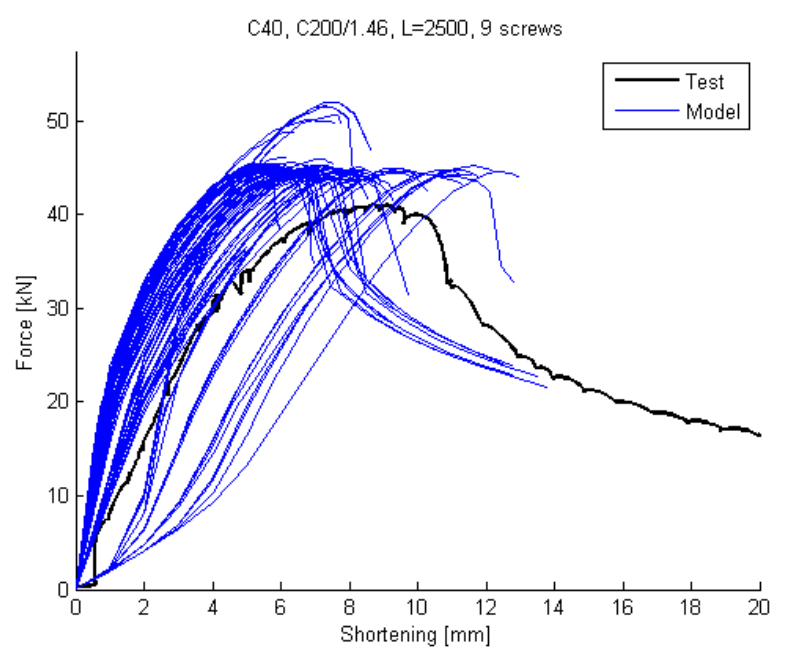

Fig. 17. Results of the parametric study (C40)
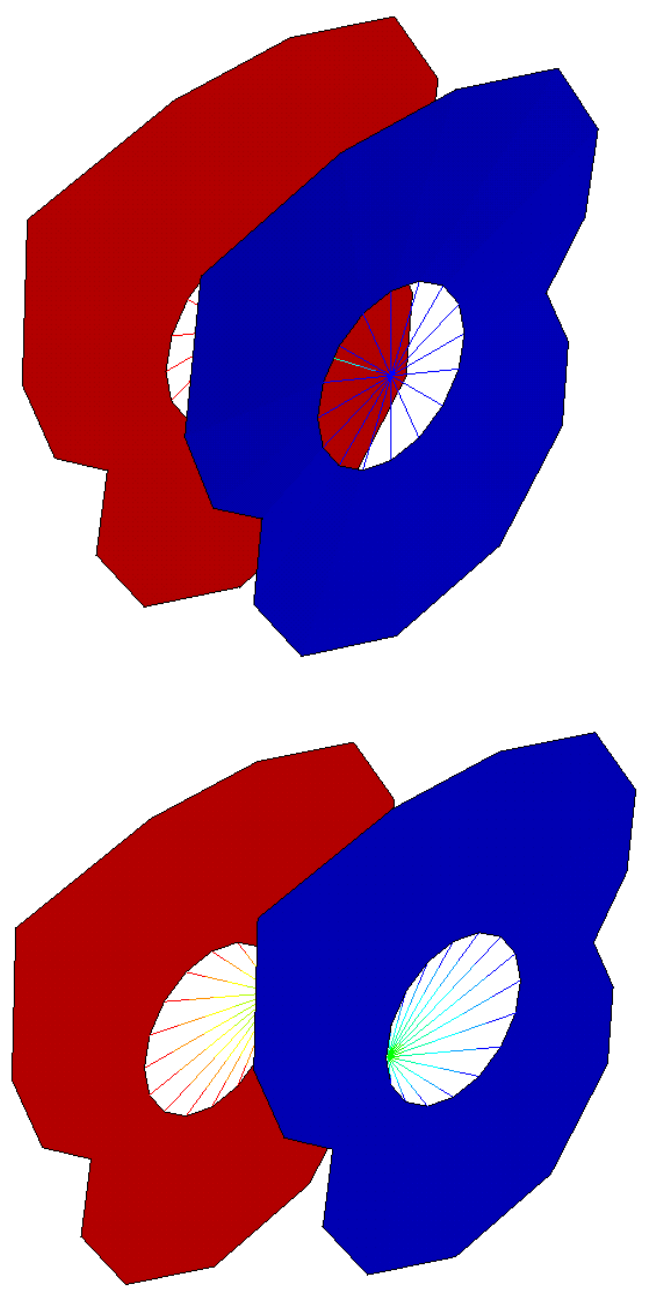

Fig. 18. Deflections of the screw models for different settings (C81). Top: rigid radial elements, shaft tilting. Bottom: rigid shaft, radial elements with small area.

sured diagrams (Figs. 20 and 21). Note, that both diagrams are obtained using the same settings of the elements of the screw model, regardless of the number of screws and thickness of the 
Tab. 5. Effect of screw rigidities on the calculated load

\begin{tabular}{lccccc}
\hline \multirow{2}{*}{ Test } & Measured load- & \multicolumn{2}{c}{ Calculated load-bearing capacities $[\mathrm{kN}]$} & \multirow{2}{*}{ Standard deviation } \\
\cline { 3 - 5 } & bearing capacity $[\mathrm{kN}]$ & minimum & maximum & mean & \\
\hline C40 & 41.02 & 43.75 & 51.97 & 45.31 & 0.0428 \\
\hline C81 & 79.23 & 90.67 & 101.63 & 93.93 & 0.0257 \\
\hline
\end{tabular}

Tab. 6. Settings of the elements of the screw model

\begin{tabular}{cccccc}
\hline Position & Element type & Area[mm $\left.{ }^{2}\right]$ & Shear area divider & $\begin{array}{c}\text { Moments of inertia } \\
\text { (bending) }\left[\mathrm{mm}^{4}\right]\end{array}$ & $\begin{array}{c}\text { Moment of inertia } \\
\text { (torsion) }\left[\mathrm{mm}^{4}\right]\end{array}$ \\
\hline Shaft element & BEAM4 & $\mathrm{r}^{2} \pi$ & 100 & $\mathrm{r}^{4} \pi / 4$ & $\mathrm{r}^{4} \pi / 4$ \\
\cline { 3 - 6 } Radial elements & & 100 & 0 & 0.01 & 1 \\
\hline
\end{tabular}

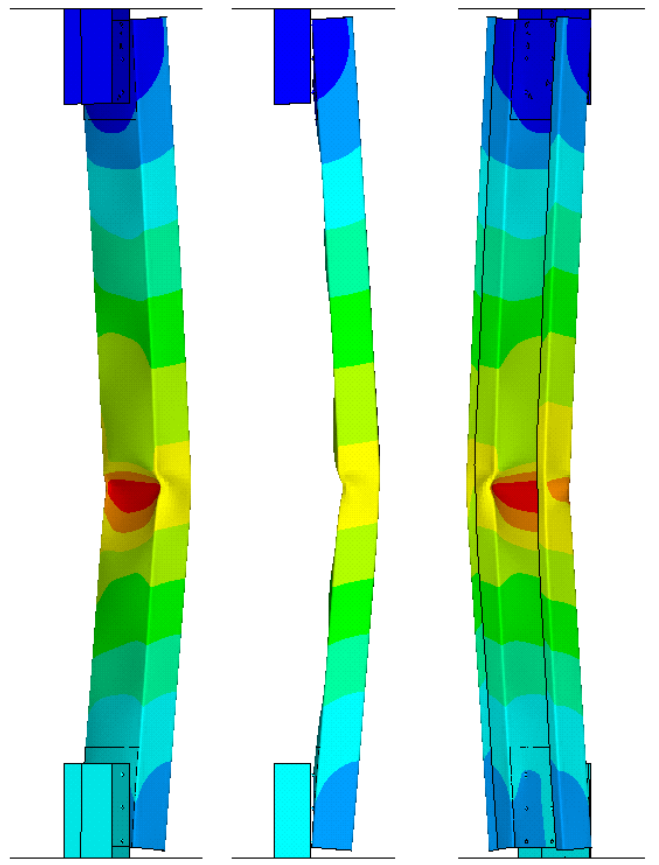

Fig. 19. Failed shape of the model (structural displacement vector sum, C81)

Tab. 7. Amplitude values used in the study

\begin{tabular}{cccc}
\hline Shape & Local & Distortional & Global \\
\hline Values & $0 ; 1 ;$ & $0 ; 1 ;$ & $0 ; 2 ; 4 ;$ \\
[mm] & $2 ; 3 ; 4$ & $2 ; 3 ;$ & $6 ; 8 ; 10 ; 12$ \\
\hline
\end{tabular}

\section{C-section member.}

\subsection{Calibrating equivalent geometrical imperfections}

An imperfection sensitivity study was carried out on the numerical models of the laboratory tests with the aim to find a set of imperfect shapes and their amplitudes that lead to an accurate reproduction of the load-bearing capacity obtained in the tests, while not affecting the failure mode. The study was carried out by applying local, distortional and global shape imperfections to the perfect model within the ranges listed in Table 7

Applying imperfections to the perfect model results a decrease of the initial stiffness of the model; hence the values pre-

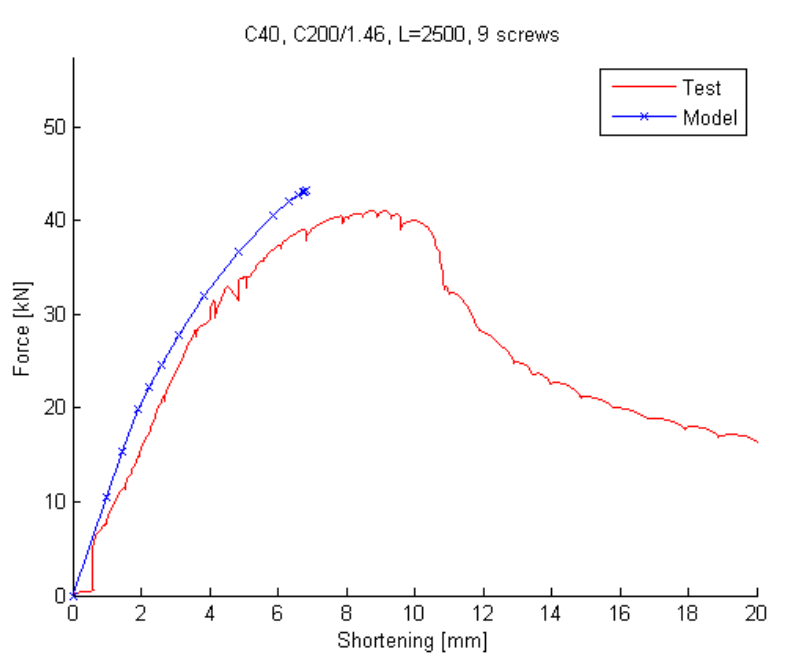

Fig. 20. Force-shortening diagram resulting from the chosen settings (C40)

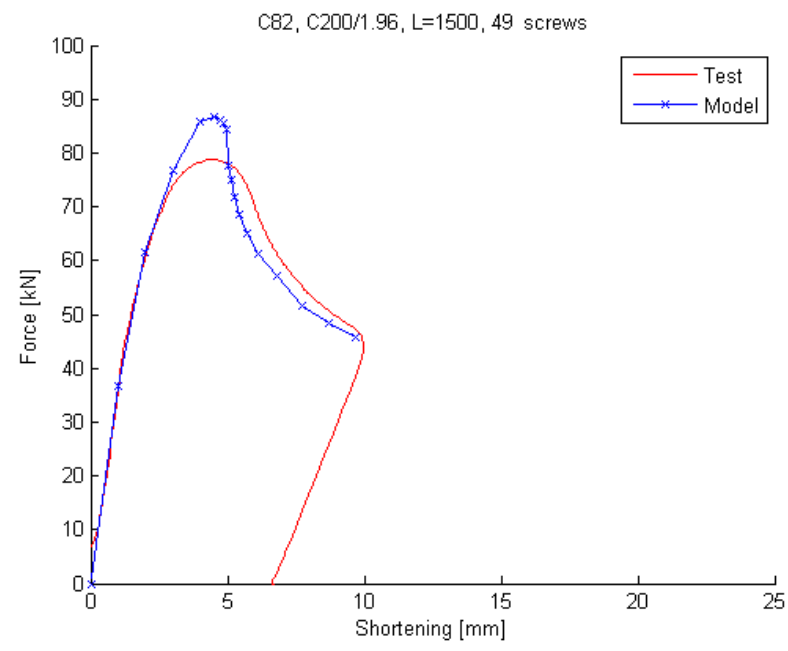

Fig. 21. Force-shortening diagram resulting from the chosen settings (C82) 
Tab. 8. Settings of the elements of the screw model in case of the imperfect model

\begin{tabular}{ccccc}
\hline Position & Area $\left[\mathrm{mm}^{2}\right]$ & Shear area divider & $\begin{array}{c}\text { Moments of inertia } \\
\text { (bending) }\left[\mathrm{mm}^{4}\right]\end{array}$ & $\begin{array}{c}\text { Moment of inertia } \\
\text { (torsion) }\left[\mathrm{mm}^{4}\right]\end{array}$ \\
\hline Shaft element & $\mathrm{r}^{2} \pi$ & 70 & $\mathrm{r}^{4} \pi / 4$ & $\mathrm{r}^{4} \pi / 4$ \\
\hline Radial elements & 100 & 0 & 0.01 & 1 \\
\hline
\end{tabular}

Tab. 9. Geometrical imperfections to be applied

\begin{tabular}{cccc}
\hline Shape & Local & Distortional & Global \\
\hline Value $[\mathrm{mm}]$ & 3 & 0 & 6 \\
\hline $\begin{array}{c}\text { Length of sinusoidal } \\
\text { half-wave }\end{array}$ & $150 \mathrm{~mm}$ & - & Member length \\
\hline
\end{tabular}

sented in Section 4.1 are to be modified in order to maintain the accordance of test and numerical results; this, as shown by the parametric study on screw model behaviour can be done by increasing the shear stiffness of the screw shaft element.

To avoid a time consuming full parametric study involving most of the tests, a wide range of imperfection amplitudes and shear stiffness, the method of successive approximation was used to determine the values providing best fit using primarily the results of test $\mathrm{C} 66, \mathrm{C} 81$ and $\mathrm{C} 82$, other tests were involved in the process only once a set providing good accordance with these three was found. This also means that a systematic parametric study was not carried out on the imperfection sensitivity of the members.

The observations made on the models' behaviour and loadbearing capacities in the study are listed as follows: i) all three types of imperfections reduce both load-bearing capacity and the stiffness of the model, ii) the amplitude of the global shape has major influence on the initial stiffness, iii) the amplitude of the local shape affects the behaviour of the model near limit point more than that of the global shape, iv) the failure mode is not affected by the imperfections with amplitudes within the studied range, v) for a given value of global imperfection the decrease of the load-bearing capacity due to the presence of distortional shape is smaller if local shape is applied than that if no local imperfection is present; the phenomenon is stronger for higher amplitude values of the local and/or global shapes. As during the tests no signs of distortional deformations were observed, distortional shape imperfections have been excluded from the investigations. Note, that the above statements are observed overall tendencies and the quantitative values of the pertinent changes depend on which test's model is studied.

The settings of the screw model found to provide good accordance of results of test and numerical model are listed in Table 8 - only the shear stiffness of the shaft element has been changed. The imperfections to be applied are summarized in Table 9

Note, that the settings presented in Table 8 and Table 9 are to be used together obtain good accordance of test and model. The proposed values of the amplitudes listed in Table 9 are fixed
Tab. 10. Specimen characteristics and test results

\begin{tabular}{|c|c|c|c|c|c|}
\hline \multirow{2}{*}{ Test } & \multirow{2}{*}{ Section } & \multirow{2}{*}{$\begin{array}{l}\text { Length } \\
\text { [mm] }\end{array}$} & \multicolumn{2}{|c|}{ Load-bearing capacity } & \multirow{2}{*}{$\begin{array}{c}\text { Ratio } \\
\text { Test/Model } \\
\text { Test/Model }\end{array}$} \\
\hline & & & Test [kN] & $\begin{array}{c}\text { Result } \\
{[\mathrm{kN}]}\end{array}$ & \\
\hline C12 & C200/2.0 & \multirow{2}{*}{2000} & 71.10 & 70.63 & 1.006 \\
\hline C15 & C200/1.0 & & 24.20 & 22.85 & 0.944 \\
\hline C23 & C200/2.0 & \multirow{2}{*}{3600} & 46.80 & 47.27 & 0.990 \\
\hline C26 & C200/1.0 & & 17.20 & 17.57 & 0.979 \\
\hline C40 & C200/1.5 & \multirow{3}{*}{2500} & 41.02 & 40.27 & 1.018 \\
\hline C41 & C200/2.0 & & 63.99 & 66.26 & 0.966 \\
\hline C42 & C200/2.5 & & 94.34 & 91.93 & 1.026 \\
\hline C66 & C200/2.0 & \multirow{5}{*}{1500} & 78.97 & 81.49 & 0.969 \\
\hline C67 & C200/2.5 & & 111.10 & 108.32 & 1.026 \\
\hline $\mathrm{C} 80$ & $\mathrm{C} 200 / 2.5$ & & 114.24 & 113.97 & 1.002 \\
\hline C81 & C200/2.0 & & 79.23 & 80.79 & 0.981 \\
\hline C82 & C200/2.0 & & 78.86 & 81.64 & 0.966 \\
\hline
\end{tabular}

values determined by the calibration of the model to yield best match of test and model results; in the studied cases the amplitude for the global imperfection it is between $1 / 250(1=1500 \mathrm{~mm})$ and $1 / 416(l=2500 \mathrm{~mm})$, for local imperfection $h_{w} / 67$.

\section{Virtual experiments}

The calibrated model was used to carry out virtual experiments on all laboratory tests with the settings of the screw model and by applying imperfections with the shapes and amplitudes described in Section 4 The resulting force-displacement diagrams are presented in Fig. 22. The obtained diagrams show, that the load-bearing capacities obtained using the calibrated numerical model are in very good accordance with the measured ones, the failure modes obtained are the same as those obtained in the tests. The comparison of test and model results is summarized in Table 10 The difference of test and model result is between $+2.6 \%$ and $-5.6 \%$ from the basis of the test result, the average is $98.9 \%$, thus the model slightly underestimates the load-bearing capacity of the test specimen.

Comparing the obtained rigidities the accordance is not uniformly good in all cases, although the majority of the tests are reproduced quite accurately. Regarding the non-matching rigidities it is suspected, that the differences are the result of measurements carried out not carefully enough, especially during the first few tests (the laboratory tests started with test C40). By 

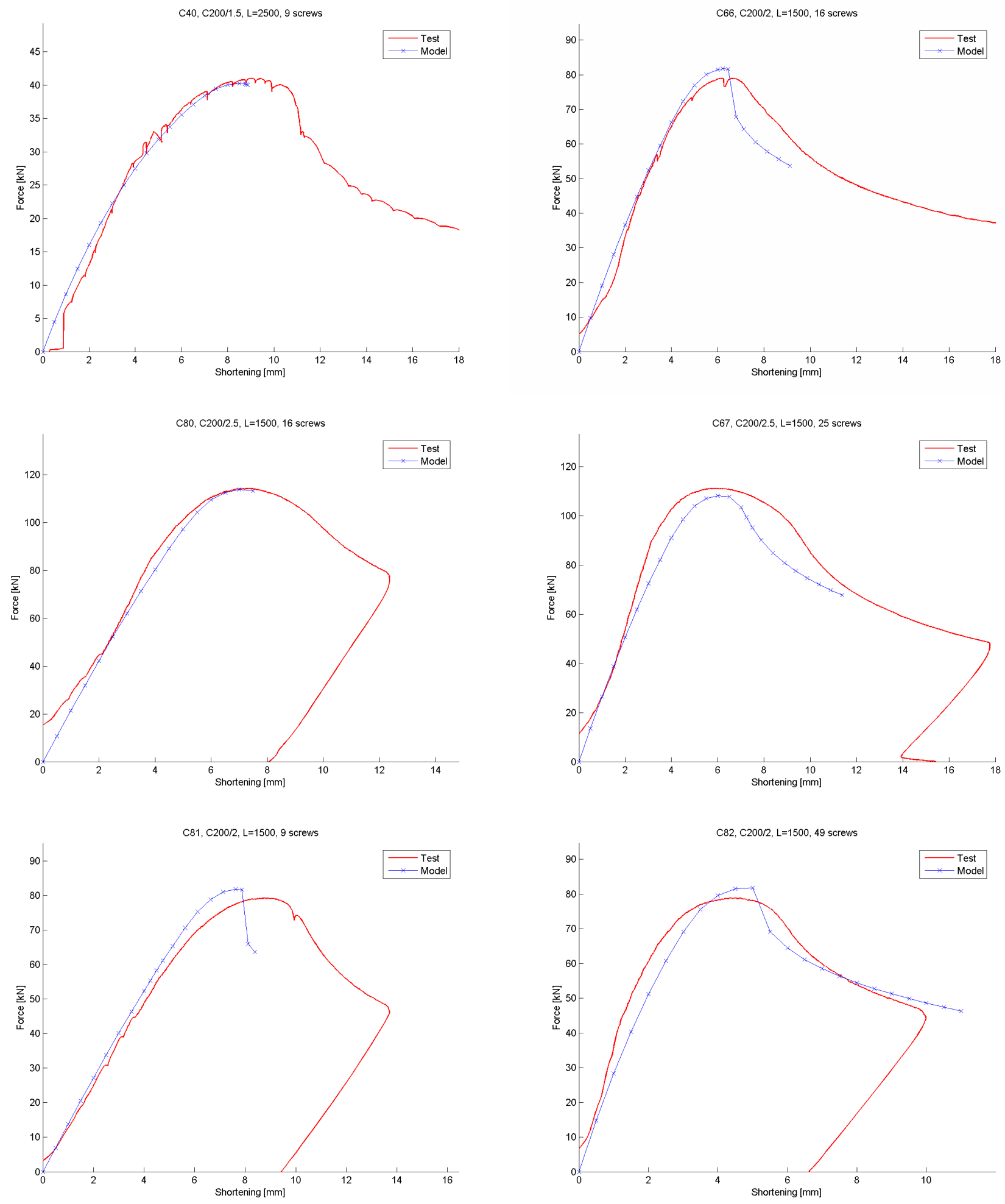

Fig. 22. Force-shortening diagrams; top left: $\mathrm{C} 40$; top right middle: $\mathrm{C} 67$; middle left : $\mathrm{C} 80$; middle right: $\mathrm{C} 66$; bottom left: $\mathrm{C} 81$; bottom right: $\mathrm{C} 82$ 
comparing the descending branch of test specimens and the pertinent models similar differences are to be observed; this is most probably caused by local effects at load introduction - in case of a denser screw layout an interaction between the screws is possible, which is a phenomenon not fully covered by the numerical model.

\section{Summary and conclusions}

In the paper laboratory tests of cold-formed C-section compression members are presented; the test arrangement is described, the behaviour and failure mode of the specimens is characterized with emphasis on the effect of applying self-drilling screws. A finite element model to accurately reproduce the laboratory tests is introduced with a focus on modelling self-drilling screws and the approach to apply geometrical imperfections to the model based on shapes derived using the constrained finite strip method.

A parametric study carried out to investigate the screw model behaviour is presented using the model without geometrical imperfections; it is shown, that the initial rigidity of the end connection can be tuned within a wide range by changing the stiffness of the elements in the screw model, but the obtained loadbearing capacity and failure mode is not affected by these. Settings appropriate to accurately reproduce the initial rigidities measured in the laboratory tests are presented; it is shown, that that the same settings may be used regardless of screw number, screw group layout and thickness of the connected plates.

An easy-to-implement approach to include geometrical imperfections in the model is presented. It is shown, that geometrical imperfections reduce both load-bearing capacity and initial stiffness of the model, but by augmenting the stiffness of the screw model the decrease in stiffness due to imperfections can be compensated, thus the model can be calibrated to provide the stiffness, load-bearing capacity and failure mode obtained in the laboratory tests. A set of settings of the screw model and geometrical imperfections is presented. The calibrated model is used to reproduce laboratory tests with a high accuracy regarding load-bearing capacity and a good accuracy regarding stiffness.

The direct result of the presented research is a numerical model capable of carrying out virtual experiments on coldformed C-section compression members; the model can be used to develop a non-conservative design method for these members. The modelling approach of self-drilling screws introduced in the paper can be used in numerical models of other types of structures of which the non-rigid behaviour of the structural joints influence the global behaviour: frames, trusses, etc. The method used to apply equivalent geometrical imperfections to the model may similarly be useful in other applications. Although both screw model and imperfections show promising results, further studies on other types of structures are necessary to prove the viability of these approaches.

\section{References}

1 Young B, Research on cold-formed steel columns, Thin-Walled Structures 46 (2008), 731-740.

2 Yua C, Schafer BW, Simulation of cold-formed steel beams in local and distortional buckling with applications to the direct strength method, Journal of Constructional Steel Research 63 (2007), 581-590.

3 EN 1993-1-5:2005 Eurocode 3: Design of steel structures. Part 1.5: Plated structural elements Annex C-FEM calculations.

4 Nédli P, Lachal A, Elastic-plastic optimum design of frames taking into account semi-rigid connections, Periodica polytechnica Civil Engineering 51/2 (2007), 51-55

5 Lógó J, Kaliszky S, Hjiaj M, Parametric survey of the influence of the semirigid connections on the shakedown of elasto-plastic frames, Periodica Polytechnica Civil Engineering 50/2 (2006), 139-147.

6 EN 1993-1-3:2005 Eurocode 3: Design of steel structures. Part 1.3: General rules and supplementary rules for cold-formed thin gauge members and sheeting.

7 Dunai L, Jakab G, Joó AL, Experiments on C/Z profile compression members, Proceedings of the Fourth International Conference on Coupled Instabilities in Metal Structures, 2004.

8 Jakab G, Dunai L, Resistance of C-profile cold-formed compression members: Test and standard, Journal of Constructional Steel Research 64 (2008), 802-807.

9 Sivakumaran KS, Abdel-Rahman N, A finite element analysis model for the behaviour of cold-formed steel members, Thin-Walled Structures 34 (1998), 115-134.

10 ANSYS 11.0, available at wWw . ansys.com

11 MATLAB R2007b, available at WWW . mathworks. com

12 Dinis PB, Camotim D, Silvestre N, GBT formulation to analyse the buckling behaviour of thin-walled members with arbitrarily 'branched' open cross-sections, Thin-Walled Structures 44 (2006).

13 Schafer BW, Ádány S, Buckling analysis of cold-formed steel members using CUFSM: conventional and constrained finite strip methods, Proceedings of the Eighteenth International Specialty Conference on Cold- Formed Steel Structures (Orlando, Florida, 2006).

14 GBTUL, available at www.civil.ist.utl.pt/gbt

15 CUFSM, available at WwW. ce.jhu.edu/bschafer/cufsm

16 Joó AL, Ádány S, FEM-based approach for the stability design of thinwalled members by using cFSM base functions, Periodica Polytechnica Civil Engineering. accepted for publication. 